\title{
Engaging Low-Income African-American Older Adults in Health Discussions through Community-based Design Workshops
}

\author{
Christina N. Harrington \\ Department of Comm. Studies \\ Northwestern University \\ Evanston, IL, US \\ c.harrington@northwestern.edu
}

\author{
Katya Borgos-Rodriguez \\ Department of Comm. Studies \\ Northwestern University \\ Evanston, IL, US \\ kborgos@u.northwestern.edu
}

\author{
Anne Marie Piper \\ Department of Comm. Studies \\ Northwestern University \\ Evanston, IL, US \\ ampiper@northwestern.edu
}

\begin{abstract}
Community-based approaches to participatory design, such as the design workshop, promise to engage underserved populations in collaborative dialog and provide a platform for promoting the views of communities who are not typically given a space to engage in design. Yet, we know little about how design workshops as a research site can engage underserved individuals (i.e., due to class, race, or age status) or address personal concerns (e.g., health). As a way of exploring these issues, we conducted a series of five design workshops with low-income African-American older adults to understand their health experiences. Our findings reveal three insights associated with the design workshop and the topic of health: comfort with community versus personal health; the sociocultural configuration of interaction; and empowerment in the context of systematic inequality of opportunity. We discuss the importance of understanding the situated nature of design workshops, particularly when engaging underserved groups in the topic of health, and the potential of the design workshop as a mechanism for activism.
\end{abstract}

\section{CCS CONCEPTS}

- Human-centered computing Participatory design

\section{KEYWORDS}

Participatory design; community-based participatory research; older adults; health; community activism

Permission to make digital or hard copies of part or all of this work for personal or classroom use is granted without fee provided that copies are not made or distributed for profit or commercial advantage and that copies bear this notice and the full citation on the first page. Copyrights for components of this work by others than ACM must be honored. Abstracting with credit is permitted. To copy otherwise, or republish, to post on servers or to redistribute to lists, require prior specific permission and/or a fee. Request permissions from Permissions@acm.org.

CHI 2019, May 4-9, 2019, Glasgow, Scotland Uk

(C) 2019 Association for Computing Machinery.

ACM ISBN 978-1-4503-5970-2/19/05...\$15.00

https://doi.org/10.1145/13290605.3300823
ACM Reference format:

Christina N. Harrington, Katya Borgos-Rodriguez, and Anne Marie Piper. 2019. Engaging Low-Income African-American Older Adults in Health Discussion through Community-based Design Workshops. In 2019 CHI Conference on Human Factors in Computing Systems Proceedings (CHI 2019), May 4-9, 2019, Glasgow, Scotland, UK. ACM, New York, NY, USA. 15 pages. https://doi.org/10.1145/13290605.3300823

\section{INTRODUCTION}

Participatory design promises to serve as a bridge between researcher and participant and engage the 'user' in addressing various societal phenomena [28, 29, 47, 48, 65]. Muller argues that participatory design can provide a "third space" wherein knowledge or expertise are exchanged between researcher and end-user [41]. Further, participatory design can encourage a unique sense of empowerment among participants [11, 20], serving as a proponent for autonomy and agency in discussions of work environment, political governance, or other life domains. This approach can aid in working through power imbalances in a number of contexts (e.g., shifting views on illiteracy or cultural norms of developing populations) [2, 65], extending its original Scandinavian application [7]. Situating participatory design within a particular community of individuals allows design to address a broader but more political set of societal challenges in a more localized context, and can effectively engage communities that face issues of access to resources [29, 44, 48].

One specific approach to participatory design is the design workshop, in which researchers collaboratively engage participants in design activities that explore phenomenological questions. Here, we extend prior work [46] by referencing the design workshop as a site and instrument for research study. The design workshop has historical precedence of serving as a democratic approach 
to innovation and development in a variety of contexts [7]. For example, recent work has aimed to engage those who are often excluded from the design of healthcare systems, such as older adults [10, 18, 24, 67] and ethnic minorities [44, 49, 59]. Engaging participants in the development of health technology systems has been shown to improve acceptance of these technologies [17, 37]. Yet, we know little about how design workshops can engage groups who historically experience systematic inequities (i.e., based on lower income, being an ethnic minority, and older age) or support discussions that are highly personal and sociocultural (e.g., health and health disparities).

The present paper aims to fill this gap in the literature through an analysis of five health-related design workshops with a community of low-income African American older adults. Democratizing the design process is particularly important given that groups who identify as marginalized based on race, ethnicity, age, gender or socioeconomic status often experience considerable health inequities when compared to non-marginalized populations (i.e., white, middle-class groups). Health disparities and chronic illnesses disproportionately affect individuals from racial and ethnic minority communities and lower income areas in the U.S. [1]. Most often, these individuals face difficulty in maintaining their health as they experience structural and systemic barriers to accessing equitable healthcare solutions such as lower incomes, poor environmental infrastructure, and lessened availability of healthier resources [30, 36]. Such structural and systemic barriers have resulted in groups who are underserved in terms of access and sustainability of healthcare resources. When compounded by age-related factors that impact health maintenance, these challenges often exacerbate gaps in health equity and access. These constraints impact how these communities approach health management and thus their perceptions of healthrelated technological interventions, making it critical to understand health needs as defined by these populations and the ways they envision solutions. Design workshops, therefore, may be a useful way to engage these individuals in collaboratively envisioning future health technologies.

The goals of the present study are twofold: (1) to understand how community-based design workshops can elicit priorities, experiences, and accounts of health among underserved communities, and (2) to examine the impact of workshop structure, method, and facilitation on the engagement of these participants. Our findings reveal three insights associated with the design workshop and the topic of health: comfort with community versus personal health; the sociocultural configuration of interaction; and empowerment in the context of systematic inequality of opportunity. Beyond this, our analysis draws on prior conceptualizations of 'making as expression' as a way of engaging people in health-related design [35] and the framing of design workshops as a research sites [46]. We extend prior work by contributing a case of how oftentimes design approaches that are participatory in theory are still implemented as a privileged, middle-class activity, making it challenged to engage underserved communities. Despite adapting activities and materials to suit the interests and sociocultural perspectives of our participants [48], we were met with challenges around what is 'successful' engagement, certain material choices being perceived as infantilizing, and inherent power imbalances. We reflect on these tensions and argue that the situated context of the design workshop has significant implications for the ways in which health is discussed and the potential to facilitate a sense of community activism around health.

\section{RELATED WORK}

\section{Community-Based Design Research}

Much like the participatory design movement, community-based participatory research (CBPR) and Participatory Action Research (PAR) focus the participant as political collaborator and catalyst for change [58]. These approaches leverage education and social action in a localized context to address challenges such as health disparities among communities of need [25, 62, 65]. CBPR and PAR as research methods do not typically emphasize design engagement, but are useful in helping researchers understand community practices prior to the integration of technology, and exploring technology solutions in the context of a particular community [23, 54]. Nevertheless, these methods share several concepts of engagement, primarily the incorporation of impacted individuals, stakeholders, and researchers in various stages of project development [58], emphasizing the need for a more inclusive and democratic approach to research.

Scholars have begun to appropriate CBPR methods into design - often termed community-based design research in order to situate design engagements in the context of a particular group or geographic location [16, 43, 44, 46, 48]. This approach is particularly useful when working with underserved communities due to diverse constraints on the ways in which people view disparities, access and resources that play into community approaches to addressing disparities, and available platforms to position and advance community needs [16, 25, 40, 44, 58]. Community-based design research is thus largely influenced by local climates of community engagement, 
making it essential to attend to the ways in which we define "community". Specifically, community may refer to a particular group based on commonalities in work or extracurricular practice, or that of individuals who share geographic proximity. Carroll highlights that community as geographic proximity presents a shared space in which individuals must negotiate living conditions, access to common resources, and cultural norms around interaction [13], which is the view we adopt in this paper. Situating participatory design in a proximate community setting can allow for a more democratic approach to design by promoting voice and perspective of the larger community. LeDantac and Fox also argue that this approach to design contends the power and authority dynamics that may exist in various community settings, leading to successful community-based interventions [16].

Turning to other examples of this approach in practice, community-based design research highlights a particular set of negotiations in collaborative design work: the cocreation of both artifact and method [26], the mutual gain that results from collaboration in CBPR [9, 22], and the ways in which participatory design through the lens of CBPR presents opportunity for social action research and activism [23, 40, 54]. Aligning the design workshop with the ethos of CBPR brings about two major points of interest: the structuring of community-based design workshops as research sites, and the ways in which the design workshop can engender empowerment among underserved communities.

\section{Design Workshops as Research Sites}

The concept of the participatory design workshop has long been intertwined with crafting, maker labs, and hackerspaces [45, 46], often focusing on a particular group's approach to collaborative work and most recently examining this approach from a sociotechnical lens of identity [39, 56, 57]. Although collaborative maker culture and participatory design overlap in some ways, the design workshop as a research site sees a slightly different structure and engagement of researcher and workshop participant [46]. In this way, the design workshop space serves as an opportunity for knowledge exchange between researcher and participant about various topics such as health, communication, or technology among a particular group based on some other defining characteristic outside of common hobby [6, 9, 46, 59]. In addition, participatory design workshops provide an opportunity to research the application of design workshop methodology itself $[6,28$, 44 , 48], highlighting the interaction of methodology and situated participant groups when examined in the context of a particular community.

Extending the methodological approaches of ethnography and anthropology, the participatory design workshop as a research site allows for observation of participant behavior as its own phenomenon [13, 45, 65], and provides researchers with a better understanding of how behaviors may be influenced by method. In this way, the participatory design workshop serves as its own social experiment into person and method, revealing nuances of engagement, power dynamics, and other social structures.

\section{Empowerment and Participatory Design}

Empowerment associated with participatory approaches to design research has been studied extensively in HCI [15, 19-21, 34, 52, 58]. Zimmerman describes empowerment as a process that helps individuals to gain "understanding and control over personal, social, economic, or political forces in order to better their lives" [68]. In this way, empowerment is represented as both a resulting sense of engagement and a nascent call-to-action. Research on community engagement and empowerment in the context of participatory design [19,48] argues that this design approach empowers community members by making local concerns more visible, focusing on local needs, and holding community representatives accountable for addressing those needs. Similarly, participatory governance and other participatory action strategies can influence change in low-income neighborhoods by focusing on the voice of the community resident in partnership with various other stakeholders [19]. This approach allows underserved groups to directly partake in decision-making that has most immediate impact on their well-being and quality of life, and thus is a common approach to addressing health disparities [32, 58, 62].

Empowerment, while often examined in terms of civic engagement among HCI researchers [15, 16, 19, 52], is described as a central theme to collectivism in health promotion in the context of CBPR and participatory design $[33,62]$. Researchers establish that participatory research approaches create local ownership of health by engaging and supporting communities that are ultimately affected by design decisions in the long run, and create opportunity for long-term community goals [32, 62]. In this way, empowerment serves as both process and outcome in community-based approaches to addressing health needs among disadvantaged and underserved groups. 
Laverack and Wallerstein suggest that in considering the concept of democratized design, it is important to examine the influence of social configuration and power relations as key aspects of community empowerment [33]. We assert that these aspects are essential factors in health promotion among underserved populations, and thus an appropriate approach to exploring health among lowincome African American older adults. It is also beneficial to understand in what ways the design workshop elicits and supports notions of empowerment.

\section{METHOD}

Our work builds upon previous work in HCI examining participatory design workshops as research sites $[16,46]$ and the ways participatory design can engage underserved individuals facing certain systematic oppressions [11, 20, 58].

\section{Design Workshop Site and Participants}

We conducted a series of five design workshops at a residential senior village where all participants lived and participated in organized extracurricular activities, providing both site familiarity and convenience for participants (see Figure 1). We intentionally decided to conduct our workshops within a community setting given that situating design work within local geographic communities is a beneficial approach to collectivism in design $[43,48]$. As our larger research agenda is to explore ways in which design can address health disparities for these individuals, we chose a community neighborhood in the Southside of that historically experiences inequalities in areas of healthcare and has a culturally complex history with the city, including racism, segregation, and resource scarcity [19, 42, 53]. Thus, we held workshops with residents of a low-income, predominantly AfricanAmerican senior village in a Southside neighborhood in Chicago.

This study was approved by the Institutional Review Board of Northwestern University. The first author spent over five months volunteering at monthly food distributions and supporting extracurricular activities at the senior village to build rapport with the community. To aid in recruitment, the first author worked with the community coordinator of the senior village to identify potential participants that may be interested by arranging in-person interest sessions for several weeks prior to the workshops where researchers visited the center and discussed the upcoming workshops and allowed interested participants to sign-up to be screened for eligibility. We also used snowball sampling, as interested participants

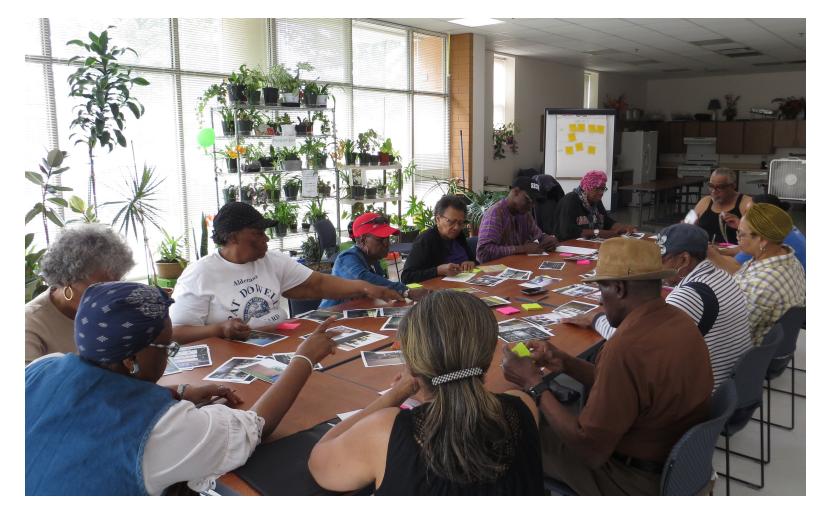

Figure 1: Participants at weekly design workshop site.

offered to share study information with others in the community.

To participate in this study, participants needed to (1) identify as African-American; (2) live in the senior village; and (3) earn less than $\$ 20,000$ annually, thus all participants fell below the local poverty line (see Table 1 for participant demographics). Using a questionnaire adapted from [14], most participants rated their health between "fair" and "good" on a 5-point scale of "poor" to "excellent". Based on questionnaire data, our participant sample identified as underserved in access to healthcare and familiarity with technology. Seven of our participants reported using the Internet about once a month for online financial or health services, including checking patient portals or medical messages from doctors. The other six did not use the Internet or go online.

Table 1. Participant Demographics.

\begin{tabular}{|c|c|c|c|c|}
\hline $\begin{array}{l}\text { ID: } \\
\text { Gende } \\
r\end{array}$ & Age & Employment & Education & $\begin{array}{l}\text { Health } \\
\text { Status }\end{array}$ \\
\hline 201: F & 71 & Retired & $<12^{\text {th }}$ grade & Good \\
\hline 202: F & 72 & Retired & High Sch. & $\begin{array}{l}\text { Very } \\
\text { Good }\end{array}$ \\
\hline 203: F & 70 & Retired & Some Coll. & Poor \\
\hline 204: F & 78 & Part-time & $<12^{\text {th }}$ grade & Fair \\
\hline 205: F & 65 & Retired & Bachelors & Fair \\
\hline 206: F & 69 & Unemployed & Associate & Fair \\
\hline 207: F & 68 & Retired & Bachelors & Excellent \\
\hline 208: F & 79 & Retired & Post-Grad. & $\begin{array}{l}\text { Very } \\
\text { Good }\end{array}$ \\
\hline 209: F & 69 & Unemployed & Some Coll. & Good \\
\hline 210: $\mathrm{F}$ & 68 & Part-time & Some Coll. & Good \\
\hline 101: M & 78 & Unemployed & $<12^{\text {th }}$ grade & Fair \\
\hline 102: M & 72 & Retired & Some Coll. & Fair \\
\hline 103: $M$ & 68 & Retired & High Sch. & $\begin{array}{l}\text { Very } \\
\text { Good }\end{array}$ \\
\hline
\end{tabular}




\section{Design Workshop Structure and Activities}

We conducted five design workshops that guided participants through a five-part exploration of perceptions, challenges, and approaches to health with the goal of informing future health technologies that may be beneficial to them individually or their community. Each workshop lasted 90-120 minutes and participants were compensated $\$ 20$ in cash for each workshop they attended. Our engagement with participants was solely as researcher-participant and co-designers as opposed to providers of a service.

Design workshop activities were selected based on prior design research workshops [46], researcher experience conducting similar sessions, and iterative feedback from participants. We first sought to have participants reflect on their ideas of health and the resources they needed in order to be healthy. We prompted this reflection through an individual collaging activity. Ads, newspapers, and magazines relevant to both the subject area of health and wellness and to the AfricanAmerican community were gathered and provided to participants. In addition, researchers provided several printed materials such as images of digital health technologies and exercise equipment, U.S. currency, stock photos of black people representing family members, and word cards that could be associated with health and wellness (e.g., spirituality, happiness, exercise, mobility). Participants were also encouraged to bring any materials that they considered meaningful to their personal health and well-being. Poster boards were prepared by the research team prior to the session, each divided into three sections with prompts to guide reflection: (1) "thoughts of health", (2) "health needs", and (3) "my health in the future".

Workshop 2 focused on documenting what health looked like and what challenges participants faced in being healthy through a Photovoice exercise [63]. At the end of the first workshop, participants were provided with disposable cameras and asked to photograph healthrelated aspects of their environment over the course of a week. During the second workshop, we provided participants with their developed photos printed on paper, which was followed by a group analysis of photos through card sorting (i.e., having participants label photos and put them into meaningful groups). While the research team suggested 'Aids' and 'Problem Areas' to health as categories, participants were encouraged to revise these, or add additional groups that they found important.

In the third workshop, participants defined potential design challenges to through a "How Might We" small group exercise. Five poster boards were provided to each of three groups, each with the open statement "How might we..." plus a verb prompt ("reduce", "increase", "make", "improve", "provide") to get the participants started. As providing more detailed instructions was one of the requests in the feedback we received weekly, the research team adapted the original activity planned by preparing print out examples. Additionally, photos from the previous week were arranged on poster boards and displayed on the walls according to participant-defined categories to guide the activity.

The fourth and fifth workshop focused on visualizing idea solutions to design challenges participants previously identified. During Workshop 4, participants individually and visually brainstormed solutions to the challenges defined in the prior week. For this workshop, participants were introduced to what it meant to represent a solution as a tool or service, based on participants' desire for more detailed instructions. Participants were then given sheets of paper separated into an ideation drawing area and lines for text, and provided with art materials (e.g., drawing paper, colored pencils). Participants were asked to ideate solutions that would address some of the prevalent "How Might We" challenges that emerged from the larger group. Lastly, Workshop 5 saw the representation of this ideation through paper prototyping and storyboarding. Participants were broken into three groups, where each group selected one of the brainstormed solutions to develop further and then represent how it would be used to address its intended challenge. During this workshop, participants were provided with large poster-sized sheets of white paper, several storyboard worksheets, markers, colored pencils, sticky notes, and other arts and crafts materials (stickers, pipe cleaners, etc.).

To frame the design engagement, we opened the first workshop with an explanation of the overall purpose: to help researchers learn and design some form of support tool for community residents' current health needs and priorities. We selected this articulation of the goal to emphasize the desire to capture participants' lived experiences, and their role in directing researchers' understandings rather than vice versa. We began subsequent workshops with a recap of the previous week and ended with an "I Like/I Wish" exercise in which participants expressed their thoughts on the workshop's activity and execution. Participants were encouraged to share feedback to improve workshops from week-to-week.

Although a few of the workshop activities were done individually (collaging, photovoice photography, solution ideation), workshops were structured in a group setting using large tables where participants faced each other to encourage sharing of ideas and materials. 


\section{Follow-Up Interviews}

To allow for further reflection on the methods and context of the design workshop with this population, we conducted one-on-one follow-up interviews with participants shortly after conclusion of the workshop series. Interview opportunities were extended to all 13 individuals who participated in the workshop series, where 12 individuals participated in follow-up interviews. These interviews focused on the perceptions and experiences of workshop participants and explored ways the workshop could promote action to problem areas that emerged. Our protocol revisited the workshop activities, setting, participant engagement, and future goals; forming our understanding of how participants interpreted this experience. Interviews lasted between 30-45 minutes and took place at the same site as the design workshops.

\section{Data Analysis and Positionality}

The research team took detailed fieldnotes and captured photographs of the workshop activities. When appropriate, we also collected video and audio recordings of participants' interactions. Following each workshop, each researcher wrote analytic memos that expanded their field notes, which were then combined to one set of memos for all workshops. We reviewed all video and audio recordings, photographs, field notes, and participant generated artifacts. We transcribed follow-up interview data and analyzed these data alongside our other workshop data. We analyzed these data streams in parallel through a process of open coding to identify initial themes across the qualitative workshop data. The research team regularly reviewed and discussed emergent themes, and then iteratively memoed on and identified resulting higher-level themes. We looked to the analytic approach of Sabiescu [48] and Rosner [46] in adopting an iterative process of reflecting on our data against the existing ideological stances of CBPR, PAR, and participatory design [44].

As both a methodological and ethical concern pertaining to research with diverse participant groups [51, 66], we disclose the identities and positionality of the researchers and authors of this paper. This series of design workshops were executed by a research team comprised of an African-American female lead researcher from a southern region of the United States (U.S.), a Hispanic female research assistant from Puerto Rico, and a white female research assistant from the Midwest region of the U.S. The third author is a white female from a rural, southern region of the U.S. All authors were involved in analysis of data and interpretation of workshop findings. As part of their own reflexive practice, the researchers worked together to constantly challenge and discuss assumptions and interpretations that emerged during analysis.

\section{FINDINGS}

Our analysis of workshop and interview data suggest three main insights into the application of design workshops for this particular population and the topic of health: comfort with community versus personal health; the sociocultural configuration of the design workshop itself; and empowerment in the context of systematic inequality of opportunity.

\section{From Personal to Community Health}

At the outset of our research, we formulated this series of design workshops as a way of drawing out personal health experiences and needs from this understudied participant group. During our first workshop session, conversations and activity engagement focused on participants' personal stories and experiences regarding their health. In Workshop 1, participants collaged about their health, visually depicting personal health issues, equipment or medications they used, their personal approaches to access doctors or healthcare, their vision for a healthier version of themselves, and the things they would need to achieve that vision (i.e. money, proper foods, etc.). As previously stated, participants were also encouraged to bring in materials and artifacts that were meaningful to them in regard to health, which in turn elicited dialogue about why certain objects had meaning and in what ways they resembled health for this population. For example, several participants brought in community health booklets they received in the mail that advertised local health services and medical equipment.

In attempts to further draw out personal health experiences and needs, our second workshop involved participants reviewing photos they took during the takehome Photovoice activity (with photo taking occurring in the time between Workshops 1 and 2). We observed, however, a distinct shift in discussion away from personal health. Although participants discussed aspects of personal health captured on their individual collage boards with the group during Workshop 1, they were reticent to discuss photos in the same way. There was a reluctance among most participants to acknowledge personal health issues or discuss particulars of these photos, leading to generalized statements, such as "these would be bad for anyone's health" or "smoking is bad for you". Many of the images participants captured depicted alcohol and tobacco consumption among other building residents and poor 
living conditions in their building and neighborhood (Fig 2). Although participants readily framed these activities as poor health habits, the conversations that surfaced upon reviewing these photos were general in nature. Moreover, there was a reluctance to claim ownership of images that depicted what the larger group deemed to be poor health habits. Despite attempts by the lead researcher, participants distanced these health habits from themselves personally. P201: I guess we don't have no personal health problems that we want to discuss. Conversations were instead re-directed to be more about the larger community or behaviors that would be considered a poor habit for "any senior". This was in direct contrast to the sharing that took place during our first collaging workshop, where personal health was discussed freely.

Instead, the second and subsequent workshop sessions became more focused on environment and community as an agent of health. Conversations emphasized the concept of health as a community practice - environmental conditions such as upkeep and sanitation in the building and neighborhood, accessible community resources, and issues of safety and community support. This may have been due to our using the resident senior village itself as a research site and conducting these workshops with a group made up of only building residents.

Workshops 2-5 involved conversations about how the surrounding environment (neighborhood, street, building) impacted feelings of safety and thus the ability to live healthily at their age. For example, one participant shared how the lack of road infrastructure in the area surrounding their building impacted their ability to get to and from doctor's appointments and grocery trips.

P201: A problem area to me is, like, crossing that street over there where we don't have a [shelter] and we're standing ... waiting for the bus ... and it's dangerous trying to get across the street to get the bus but we don't want to stand out there in the rain and the snow so we stay on this side so now we have to fight to get across ... to me, that's a danger right there.

Many participants also expressed concern for local violence prevention, a determinant which has traditionally been shown to impact community health in low-income
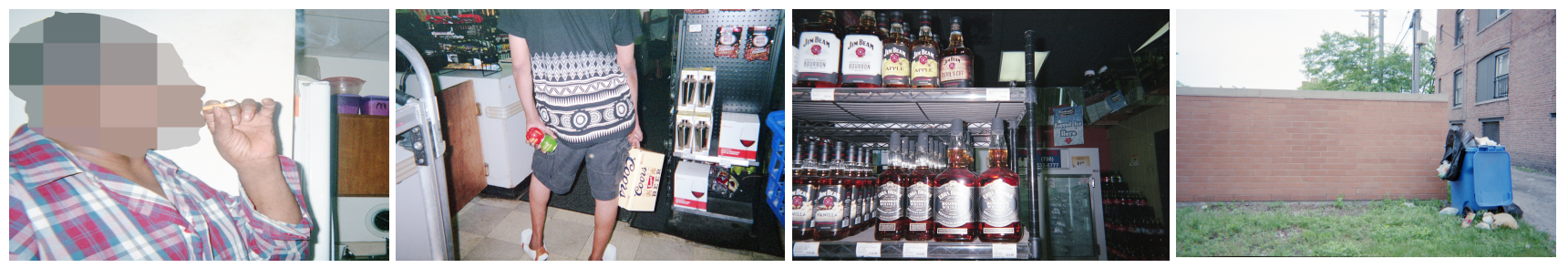

communities [40]. Further, the shift away from personal health calls attention to the private and intimate nature of health when localized in a particular individual rather than a social group or organization. Many participants expressed in follow-up interviews that they would feel more comfortable discussing personal health with complete strangers, certain family members, or close friends that did not live in proximity to them. Participants explained their reluctance to discuss personal health and perceived poor health habits with community peers they would see every day as a result of pre-existing social dynamics and history of familial disclosure about health, whether good or bad.

P204: Like I said, there's too much talk... it's just too much talk... And they tell other people's business. If we was in here, and talked about something... when you go out there, a day or two may pass, then somebody asks, "come in, let me ask you something”. You know... I don't trust people in here.

Participants indicated that personal health was a subject too intimate to be engaged with for participatory design workshops configured within this particular social community. Follow-up interviews disclosed that for many participants this stemmed from their personal bouts with chronic illness or drug use that they would not want shared with people they saw every day. Confidentiality thus emerged as a major concern for discussing intimate details of one's personal health in the setting of design workshops. The emphasis on community health and distancing from a focus on personal health reveals the ways in which the structure of design workshops influences conversations on health experiences and needs. Here, we see not only that individual health is a personal issue, making it sensitive to group discussion, but that the social configuration of the group raises additional confidentiality considerations for the orchestration and facilitation of design workshops as a research method for understanding health. We see through our analysis, and our decision to hold workshops with residents within a single residential community, that the site of research cannot be separated from the social context of the workshop, which forms a backdrop for engagement.

Figure 2: Participant photos of health within their community during Workshop 2 Photovoice activity. 
Considering the design workshop as a "situated instrument of innovation" [46] frames the way in which we understand both engagement and outcomes, a key underpinning of community-based design work [16]. The situated location of our workshop site influenced the content of the workshop in such a way that the constructs of health and community, both social and material, cannot be disentangled.

\section{Sociocultural Configuration of Participation}

When conducting community-based participatory design, it is vital for researchers to allow for re-configuration of tools, spaces, and activities themselves as they learn the local culture of participants [48, 49]. Prior to and throughout our design workshops, the research team discussed the aspects of the workshops that would in essence 'configure participation' [60]. At the most basic level, we were sensitive to the sociocultural dimensions of activities by examining whether materials, prompts and instructions were in a form that was relevant and digestible for workshop participants. For example, we sought to provide geographically relevant magazines and flyers (e.g., Penny Saver ads) during collaging that would be hyper-local to the population engaging in the workshops. This consideration extended to the format of activities and complexity level of materials, in which we constantly monitored how participants reacted to both the material selection and physical configuration of the workspace.

An interesting tension that emerged across the workshops was the desire for simplicity in ideation materials coupled with the expression of feeling that certain materials (e.g., colored pencils or markers) made participants feel as though they were engaging in "elementary activities". Based on observations during the first three workshops, we realized that ideation activities might be best supported by facilitating conversation with participants about the ways they wanted to visually express their ideas. While many participants felt they had little context to inform responses to this discussion, a few commented that "arts and crafts materials" similar to those available during collaging would be useful to showcasing ideas. Ultimately, we adapted our plans to leverage a variety of materials that ranged in fluidity and potential for expression [35] (e.g., paper, markers, magazines clippings), and practices with which participants were familiar and comfortable performing (e.g., artistic collaging, taking pictures). However, a few participants felt that the presence of these materials indicated that the researchers perceived participants as incompetent or inexperienced, likening this engagement to that of "little kids coloring in coloring books" [P201]. We see an inextricable link between social expectations and material appropriation, and find that these constructs are rooted in the sociocultural associations participants bring to bear on an engagement. As others have noted, attending to and making adjustments based on such sociocultural associations is essential to engaging diverse populations in participatory design [26, 48, 49].

Although we aimed to strike a balance in the kinds of materials we provided for each activity, participants felt that there were gaps in what we provided. In the collaging activity for example, participants desired images that represented negative feelings regarding health and various stages of feeling sick or disabled. Many participants felt that in showing themselves in collages or storyboards it was important to show a realistic depiction of how they felt on average. P204: It's important for me to show myself how I feel, cuz some seniors don't think about it and don't try to look better or do better. Additionally, there was an emphasis placed on having more representation of money as this was perceived as both a catalyst and barrier for health among the group. In the collaging activity, this was indicated by each participant using images of money throughout their collage boards. Following this common use of imagery, participants explained that finances prevented them from accessing things such as health insurance, necessary medications, and proper nutrition. The overwhelming use of visual imagery depicting money provides a clear signal of the tension between the dependence on and lack of access to money for health shared among the group.

Just as sociocultural associations with materials shaped participation and elicitation of participant experiences, so did social expectations and norms for engagement in the concept of a design workshop itself. One emergent social configuration was the formation of informal leaders during workshop activities. Our workshop structure, specifically the choice of group activities and arrangement of large group tables, was intended to encourage collaborative participant interaction. However, in some instances we observed the emergence or designation of one or more leaders or "speakers" for the larger group. At certain points this engagement took the form of an informal group leader translating their perceived understanding of design activities, and at other points these leaders made design decisions on behalf of the group. Thus, informal group leaders shaped participation through both acts of facilitation and the narrowing of possible design futures. The theme of leadership was also felt in workshop participants looking to researchers as instructors to help guide their engagement. During follow- 
up interviews participants expressed a desire for researchers to provide detailed instructions on how an activity should be executed and insight on the direction of the solution.

In our observations, the emergence of group leaders and the expressed preference for instructional guidance appeared to be tied to participants' perceptions of their education level and experience. Some participants felt that their ability to be vocal in design activities was limited due to them not being educated enough. Others expressed that their thoughts or level of familiarity with these types of activities prevented them from providing "good" ideas. Participants suggested that group leaders could guide their group to a "successful" outcome, stating things such as "her brain works better than mine, I'll let her lead" or "she does this more often that I do". While previous studies suggest that it is not uncommon for hierarchical relationships to exist in the context of participatory design work [11, 26, 48, 49], this phenomena has primarily been explored in developing countries with different social norms for interpersonal interaction. Here, we observe a tendency to relegate leadership based on participants' perceptions of ideal education, intellect, and experience.

The notion of a "successful outcome" for participatory design has been challenged in prior work [12] and is felt by participants in our design engagements. The thought that there is a "right or wrong" solution or approach extended throughout our participants' understandings of activities and how they engaged in them. Participants in our workshops seemed to focus on whether they were visually representing ideas correctly, creating the right types of drawings, or capturing the correct objects of their photo project. In our debrief interviews, participants expressed a desire to have more of a concrete idea of what the researcher considered "right or wrong" in brainstorming or ideating solutions, echoing results from CBPR work with low-income minorities [25, 44].

P201: That's the hardest part is not knowing what it is that you're looking for, what it is you want. So you don't know how you going to put your brain together for this. This is something that you never did, you're not used to it. We tried to fit in what we thought you might want.

During solution brainstorming and mockups, participants had a hard time thinking beyond ideas or solutions with which they were already familiar. Previous analyses of participatory design methodology suggest that the concept of creativity may be difficult for those not familiar with the design process [50], particularly among older adults, minority groups, or others who may feel they lack a certain knowledge to be creative [17]. The common sentiment that there was a right or wrong answer, was also seen in the critique of "wild ideas" as ridiculous or out of scope. When prompted to think of "blue sky" ideas that may push the boundaries of participants' imaginations, participants of our workshops responded to peer ideas that they considered to be "crazy" or "ridiculous" with criticism and mocking. During Workshop 3's "How Might We" activity, participants were asked to think of solutions to increase their access to healthcare. One participant suggested an emergency room that could be located in the first floor of the senior village. This caused an uproar among other participants with laughter and yelling, expressing that solution as incorrect to what was being asked. Rather, conversations seemed to center on ideas that were feasible from participants' perspectives or preexistent, even when encouraged to think "outside of the box."

During solution brainstorming, participants had a hard time thinking beyond resources they were already familiar with. Oftentimes, participants expressed that they were not sure what a proposed solution should look like outside of existing public and local health services. For example, when brainstorming solutions for better communication of health-related information to healthcare professionals, one participant expressed that it would be difficult for the larger group to think of things outside of simply communicating verbally with the doctor in person. P201: We don't know any other way to tell the doctors about our health other than using our mouth in the doctor's office. That's the only way.

The challenges seen here in participants' creative ideation indicate the importance of researchers understanding and acknowledging what is considered familiar among research participants. However, the tendency to focus on the familiar and known, or limited vocal engagement during design activities, as seen among our workshop participants, should not be viewed as a less desirable path to envision design futures. Aligned with Rosner [46] and other recent studies examining engagement in the design workshop [17, 38, 55], we challenge the notion of a uniform style of participant engagement or creativity. Instead, we suggest that emphasizing the elicitation of out-of-the-box and futureoriented ideas may marginalize the essential and practical ideas that are central to the lives of underserved communities.

\section{Empowerment and Systematic Inequality}

Empowerment emerged as a salient theme across all of the design workshops. Workshop participants consistently expressed that engaging in workshop activities allowed 
them to think more expansively about health and methods to address health challenges. Here, the concept of empowerment emerged in three different ways: empowerment to participate in and take ownership over design workshops themselves; empowerment of the individual to own their health choices and management; and community empowerment towards a collectivist and activist approach to social and environmental determinants of health. We engage the concept of empowerment from the perspective of action, or power-to [52], as defined by Schneider as a means to encourage personal ownership of health decisions.

First, a sense of empowerment emerged through participant engagement in altering workshop activities and materials, providing participants with a sense of ownership over the direction of the design workshop itself. Throughout our design engagements, researchers regularly sought participants' guidance on how the workshops should unfold, and in turn, participants provided input as to which areas of health they wanted to focus on, stating that some areas were more immediately pressing and relevant to them than others. This is evident in the shift from personal to community health:

P207: ... [we] want a broader perspective of health in general, and not so much focused on the individual, but on the people around the individual. That means family, that means the neighborhood, that means more than just an individual.

Additionally, we regularly asked participants about their perception of workshop materials and approaches for visualizing solutions, allowing researchers to shift to materials and activity approaches that would be tailored to participant experiences and backgrounds. This ongoing, open dialog between researchers and participants seemed to promote participant "buy-in" to the actual activities themselves, promoting a sense of empowerment through collaborative design of the workshop activities themselves.

Second, a sense of empowerment to own health choices was observed in different ways, including individuals feeling that activities encouraged realistic approaches to their current health practices, or that they were introduced to areas of their health that they had previously not considered. Many participants commented that this stemmed from the structure of the design workshop feeling "informational," and done in such a way that they felt they were learning about new approaches to sustaining their health. This structure of the design workshop may also encourage a sense of ownership over personal health practices and outcomes as a result of this knowledge sharing. Such autonomy in health decision- making presents a tension in the history among lowincome African-Americans to rely on institutional medical resources as the ultimate authority in their health $[5,61]$. Our participants expressed that the decision-making regarding health maintenance should be something that older adults engage in more. As P102 explained, Sure, I think they should have a say. Definitely. I mean, it's your health and if you ain't got a say, you got other people making choices for you. You should be able to make your own choices.

Third, and most notably, empowerment in the sense of community activism and collectivist approaches to health emerged as a theme from our workshop series. Participants felt that activities such as Photovoice in Workshop 2 helped them to "get out and see their community" and "capture things that were meaningful to their health", establishing a firsthand lens on their environment and the ability to define problem areas in a meaningful way [63]. Participants also commented that engaging in the design workshop helped them to see that they could approach these issues as a community.

P102: I learned that we could make some changes if we work collectively instead of just trying to do things on our own I mean, I always knew that, but it seemed like we couldn't get people to do that. It's one thing to know something, but then it's another thing to do it. We were actually doing some things to make changes.

Defining and brainstorming community health solutions also brought about a sense of activism among the group to implement change for things that had been

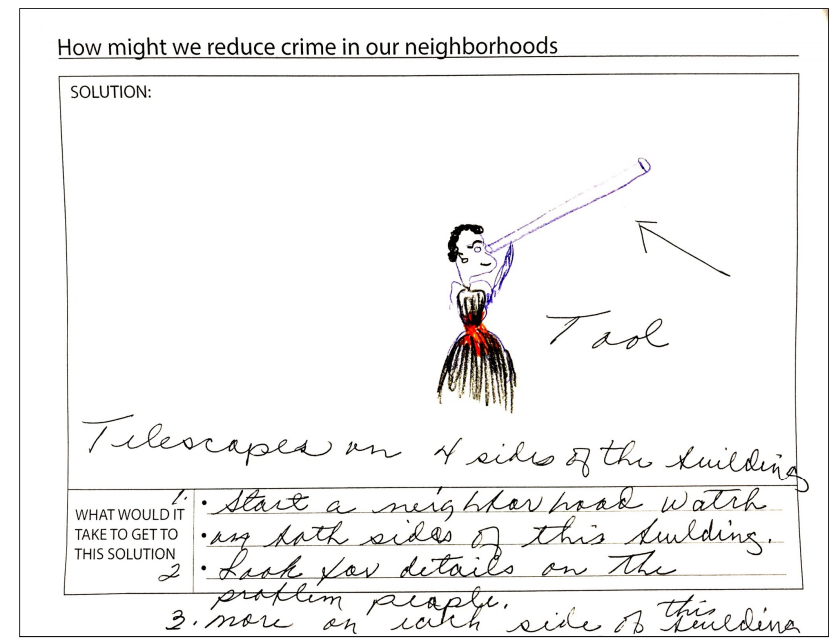

Figure 3: Workshop participant's solution brainstorming of how to reduce crime in the local neighborhood. Image depicts woman using telescope for neighborhood watch. 
long-standing problems in the community. Brainstorming and ideation activities quickly progressed into participants discussing ways in which they could better their community and residential senior village, such as petitions to building management to address structural building issues, or a neighborhood watch and anonymous photo submission system to address neighborhood crime (Fig. 3).

Participants expressed that discussing community health challenges as a group led them to think critically about ways to address health issues that have been longstanding problems. One participant said, "I'm glad we discussed some of these things," and another echoed, "I liked that it seemed some of these things can actually get done." When asked in follow-up interviews if participants felt that older adults should be involved in designing solutions for their health, many participants commented that engaging in designing solutions for their health would help them be more invested and perhaps consistent with health maintenance, echoing prior work [18, 24]. This sense of investment in individual involvement as activism related to community health also led participants to urge for action to take place following the workshops. Participants felt that design workshops could be a very useful tool in addressing community health concerns if they were: held consistently with more engagement from community residents; addressed areas that were immediately relevant; and informed community residents on how they could move forward with action to implement solutions designed during the workshop.

P102: Definitely more needs to happen, otherwise it's just talk, we just brainstorming, thinking about things, we're putting things out there, but where do we go from here? What's the next step? Things need to start getting done, the things that we talked about. Not just we talked about it and then that's as far as it's going to go. That's what's been happening. We been talking about we need more jobs in the community, how long we been talking about that? Ever since Martin Luther King. I mean, that's always been a problem.

This focus on empowerment and being an agent of change speaks to a sense of community activism that participants seemed excited about across each design workshop; however, this sense of empowerment and making change is situated against the backdrop of systematic inequality and local cultural context. Solution brainstorming among participants centered on the abilities and actions of community residents themselves and less on needing law enforcement or local governance and leadership to create such change. For example, participants formulated plans to start a petition to building management about their current living conditions and concerns of neighborhood upkeep and safety. Although existing literature highlights participatory design and the design workshop as a lens to examine the utilization of readily available community resources as assets [19], participants of our workshops expressed that existing resources that were available to address these concerns (neighborhood crime and upkeep) such as 311 and the police were often unresponsive in their neighborhood and other low-income environments. Thus, participants ideated solutions and actions that could be upheld among community residents themselves. It is also beneficial to consider the history and current climate of relations between police and African-American community residents in the area where our workshops were conducted. This climate is currently associated with distrust and skepticism of law enforcement and local governance [53, 64], which was also stated as a reason for participants not wanting to solely rely on existing law enforcement as a solution.

P206: A little while back, we had a meeting with [the police] ... you remember, when they were talking about having those lights right here on the corner, the cameras... does anybody remember? Group: Yeah, [we] remember. P206: Well, what happened? Nothing...

This inclination to focus on ideas that participants themselves could execute and uphold helps understand why participants may be less willing to engage with "wild" or "blue sky" ideas during brainstorming. That is, participants are thinking practically about their own ability to see these ideas to fruition given their resource constraints, experience with authority, and position in society. Participants commented that ideating crazy ideas was "impractical" because those solutions would not actually happen. Oftentimes local government resources that are put in place to support community maintenance (e.g., city call centers, town halls) are not as supported in low-income neighborhoods or communities of color [40], presenting a particular tension between ownership of community health maintenance and the systematic inequalities that challenge that ownership. This tension may be heightened among older adults as there is a perception that in older age health is out of the individual's control and guided primarily by healthcare professionals, leading to a reliance on a doctor or nurse as authoritative knowledge [3, 4].

As participatory design serves as a catalyst for social action in various areas, we find that engagement in design workshops seemed to have the impact of exposing community residents to ways that they could take 
ownership over actions and decisions regarding their health. Our findings suggest that directly involving individuals that are most affected by design decisions in conceptualizing, brainstorming, and ideation processes is a promising way to address health equity and disadvantage while fostering a sense of empowerment at multiple levels.

\section{DISCUSSION}

Our analysis is framed by examining the design workshop as a research site. Through this view, we articulate the ways in which the setting and structure of the design workshop and its situatedness within a community impacts participant engagement with the topic of health. Further, our results highlight the ways in which the design workshop can serve as a mechanism for community health activism and provide insights into future participatory design research.

\section{Situated Context of Design Workshops}

Our analysis of this particular community and discussions of health provides a novel case of how the social dynamics of a group and local community affect design engagements $[15,16,44,46,48,65]$. In examining the design workshop as a research site, we observed that the topic - in this case health - and the situated context of the workshop itself cannot be disentangled. In particular, we found that disclosure of illnesses, personal health behaviors, and health history or experiences was considered too intimate to discuss among the group, despite commonalities among workshop participants. Instead, the social dynamics and norms within this community gave rise to issues of confidentiality and discomfort in personal health discussions, particularly discussions that might reveal past health behaviors (e.g., drug use) that go against social norms.

Beyond the social dynamics of a particular community, it is important to understand the broader sociocultural context of the individuals brought together through the design engagement and how it shapes participation. This is particularly important for discussions of health, in which sociocultural perspectives have been crucial in revealing health perceptions and concepts of low-income and minority groups $[27,30,31,43]$. While other participatory design engagements with older adults demonstrate successful explorations of personal health topics such as symptom tracking and condition monitoring $[18,24,67]$, our data suggests a preference to focus on community health and disparities in access to care - themes that have been highlighted by sociocultural perspectives on health in communities of low-income people of color [32, 62]. On one hand this might suggest that participants' sociocultural perspectives of health, along with the collectivist nature of resident collaboration on design ideas, led to a focus on community health. On the other hand, activity structure and workshop size likely also played a role, as our workshops were convened as groups in a community-oriented location.

\section{Design Workshops as Mechanisms for Activism}

Workshop discussions revealed the perception of environmental and social inequalities that participants felt were associated with their sociocultural positioning. As such, much of our design engagement featured conversations about addressing community health issues through social action due to an extended history of lack of resources and feelings that residents could not rely on local government. Extending the work of CBPR as well as social action research $[62,65]$, our work recognizes participant engagement in design workshops as a platform for community activism. The participatory design movement has its initial origin in the inclusion of local communities in political processes for social and economic empowerment and "democracy at work" and has progressed into a method of democratizing innovation and system development [7, 8]. A defining characteristic of participatory design as a method is the centering of empowerment and democratic participation [14], which we see as a strong argument for the inclusion of individuals in the design process who may otherwise be excluded, particularly those facing systemic inequality. Thus, we must further question what constitutes a product of participatory design [12] and how participants take action through design. In particular, identifying solutions such as petitions to building management and community programs that the residents themselves can uphold serve as highly "successful" products of design engagements when the goal is empowerment and social activism. Our participants identified local community resources as approaches to health access, mentioning existing transportation resources or food services. This highlights the ways in which design workshops can make visible local or community resources and support collective thinking around resource access [43]. This is particularly important in community settings where resources are limited, and sustaining design solutions is uncertain. This engagement mirrors the collectivist outcomes of Participatory Action Research in that it sees the acknowledgement and development of equitable community-based solutions that aim to develop local residents as active co-researchers and implementers of change. 


\section{Implications for Future Research}

Despite the potential for the design workshop to support a democratic approach to innovation and political engagement, there are several ethical and methodological considerations. In particular, we must be critical of how design engagements can foreground researchers as empowering participants instead of community empowering community. Researchers must also consider the ways in which their own privilege and assumptions underlie and set priorities for community-based design efforts. Even with a concerted effort to provide culturally sensitive materials and adapt to participant feedback, we still faced challenges in terms of negotiating a desire for participant creativity and what they perceive as valued by researchers. The choice of certain materials can seem engaging to some while others may interpret this as alienating or infantilizing [35]. Thus, we point to the need for a collaborative research agenda that centers community partnership in developing the research plan and structure of design workshops similar to Participatory Action Research, as there is evidence that community activism is supported through communal connections and collaborations [16]. And, this early emphasis on community partnership and the notion of mutual gain may be, in part, what helps participants sustain engagement and realize proposed social action initiatives beyond workshop participation [9, 22].

\section{CONCLUSION}

This paper contributes a case analysis of design workshops as a research site, focusing on how this approach stands to engage low-income African-American older adults in health discussions. Our results identify the ways in which design workshops can support this community in ownership of their health, suggesting community health activism as a focus of interest. Extending prior work, we argue that community-based participatory design should extend beyond the focus of the artifact being designed and technocentric views of what constitutes design success. Instead, designers and researchers should leverage community-based design workshops as a vehicle to simultaneously understand and influence not only potential health outcomes, but also provide a platform for the social and political outlooks of underserved individuals.

\section{ACKNOWLEDGEMENTS}

We acknowledge the participation of our community partners at The Renaissance Collaborative Senior Village in Chicago for their assistance in this research. This work was supported in part by NSF grant IIS-1551574.

\section{REFERENCES}

[1] African American Health: 2017.

[2] Andrea, V.D.' and Teli, M. 2010. Teaching Participatory Design: A Participatory Approach. PDC '10: Proceedings of the 11th Biennial Participatory Design Conference (2010), 223-226.

[3] Angel, J.L. and Angel, R.J. 2006. Minority Group Status and Healthful Aging: Social Structure Still Matters. American Journal of Public Health. 96, 7 (2006), 1152-1159. DOI:https://doi.org/10.2105/AJPH.

[4] Banerjee, D. et al. 2010. Self-reported Health, Functional Status and Chronic Disease in Community Dwelling Older Adults: Untangling the Role of Demographics. Journal of Community Health. $\quad 35, \quad 2$ (2010), 135-141. DOI:https://doi.org/10.1007/s10900-009-9208-y.

[5] Banks, K.H. and Kohn-Wood, L.P. 2002. Gender, Ethnicity and Depression: Intersectionality in Mental Health Research with African American Women. African American Research Perspectives. 6, (2002), 174-184.

[6] Binder, T. and Brandt, E. 2008. The Design: Lab as platform in participatory design research. CoDesign. 4, 2 (2008), 115-129. DOI:https://doi.org/10.1080/15710880802117113.

[7] Bjerknes, G. et al. 1987. Computers and democracy: A Scandanavian challenge. Gower Pub Co.

[8] Björgvinsson, E. et al. 2010. Participatory design and \&quot;democratizing innovation\&quot; PDC '10: Proceedings of the 11th Biennial Participatory Design Conference (2010), 41-50.

[9] Bossen, C. et al. 2010. User gains and PD aims: Assessment from a participatory design project. PDC'10: Proceedings of the 11th Biennial Participatory Design Conference (Sydney, Australia, 2010), 141-150.

[10] Botero, A. and Hyysalo, S. 2013. Ageing together: Steps towards evolutionary co-design in everyday practices. CoDesign. 9, 1 (2013),

$37-54$. DOI:https://doi.org/10.1080/15710882.2012.760608.

[11] Braa, J. 1996. Community-based Participatory Design in the third world. PDC'96: Proceedings of the Participatory Design Conference (1996), 15-24.

[12] Bratteteig, T. and Wagner, I. 2016. What is a participatory design result? Proceedings of the 14th Participatory Design Conference on Full papers - PDC '16 (2016), 141-150.

[13] Carroll, J.M. 2001. Community computing as human - computer interaction. Behaviour \& Information Technology. 20, 5 (2001), 307-314. DOI:https://doi.org/10.1080/01449290110078941.

[14] Correia, A.-P. and Yusop, F.D. 2008. \&quot;I Don't Want to be Empowered:\&quot; The Challenge of Involving Real-world Clients in Instructional Design Experiences. PDC '08 Proceedings of the Tenth Anniversary Conference on Participatory Design 2008 (Bloomington, IN, 2008), 214-216.

[15] Le Dantec, C. and Edwars, K. 2008. Designs on dignity: Perceptions of technology among the homeless. CHI '08. Proceedings of the Twenty Sixth Annual SIGCHI Conference on Human Factors in Computing Systems. ACM.

[16] Le Dantec, C.A. and Fox, S. 2015. Strangers at the Gate: Gaining Access, Building Rapport, and Co-Constructing CommunityBased Research. CSCW '15: Proceedings of the 18th ACM Conference on Computer Supported Cooperative Work \& Social Computing (Vancouver, BC, Canada, 2015), 1348-1358.

[17] Davidson, J.L. and Jensen, C. 2013. Participatory Design with Older Adults: An Analysis of Creativity in the Design of Mobile Healthcare Applications. Proceedings of the 9th ACM Conference on Creativity \& Cognition - C\&C 13 (Sydney, 2013), 114-123.

[18] Davidson, J.L. and Jensen, C. 2013. What health topics older adults want to track. Proceedings of the 15th International ACM SIGACCESS Conference on Computers and Accessibility - ASSETS '13 (2013), 1-8.

[19] Erete, S. and Burrell, J. 2017. Empowered Participation: How 
Citizens Use Technology in Local Governance. CHI '17 Proceedings of the 2017 CHI Conference on Human Factors in Computing Systems (Denver, 2017), 2307-2319.

[20] Ertner, M. et al. 2010. Five Enunciations of Empowerment in Participatory Design. PDC '10: Proceedings of the 11th Biennial Participatory Design Conference (2010), 191-194.

[21] Galliers, J. et al. 2012. Words Are Not Enough: Empowering People With Aphasia In The Design Process. PDC '12: Proceedings of the 12th Participatory Design Conference (2012), 51-60.

[22] Garde, J.A. and Van Der Voort, M.C. 2014. Participants' view on personal gains and PD process. PDC '14: Proceedings of the 13th Participatory Design Conference (Windhoek, Nambia, 2014), 7982.

[23] Ginossar, T. and Nelson, S. 2010. Reducing the Health and Digital Divides: A Model for Using Community-Based Participatory Research Approach to E-Health Interventions in Low-Income Hispanic Communities Introduction and Background. Journal of Computer-Mediated Communication. 15, (2010), 530-551. DOI:https://doi.org/10.1111/j.10836101.2009.01513.x.

[24] Harrington, C. et al. 2018. Designing Health and Fitness Apps with Older Adults: Examining the Value of Experience-Based Co-Design. PervasiveHealth '18: 12th EAI International Conference on Pervasive Computing Technologies for Healthcare (New York, 2018).

[25] Horowitz, C.R. et al. 2009. Community-Based Participatory Research from the Margin to the Mainstream: Are Researchers Prepared? Circulation. 119, $19 \quad$ (2009). DOI:https://doi.org/10.1161/CIRCULATIONAHA.107.729863.

[26] Hussain, S. et al. 2012. Participatory Design with Marginalized People in Developing Countries: Challenges and Opportunities Experienced in a Field Study in Cambodia. International fournal of Design. 6, 2 (2012), 91-109.

[27] Joseph, R.P. et al. 2017. Designing Culturally Relevant Physical Activity Programs for African-American Women: A Framework for Intervention Development. Fournal of Racial and Ethnic Health Disparities. 4, 3 (Jun. 2017), 397-409. DOI:https://doi.org/10.1007/s40615-016-0240-1.

[28] Joshi, S.G. and Bratteteig, T. 2016. Designing for Prolonged Mastery. On involving old people in Participatory Design. Scandinavian fournal of Information Systems. 28, 1 (2016).

[29] Kapuire, G. et al. 2014. Community-based co-design in Okomakuara A contribution to "Design in the wild." Proceedings of the 13th Participatory Design Conference (2014), 207-208.

[30] Kreuter, M.W. et al. 2003. Sociocultural Characteristics and Responses to Cancer Education Materials among African American Women. Cancer Control. 10, 5 suppl (Sep. 2003), 6980. DOI:https://doi.org/10.1177/107327480301005s10.

[31] Kreuter, M.W. and McClure, S.M. 2004. The Role of Culture in Health Communication. Annual Review of Public Health. 25, 1 (Apr. 2004), 439-455. DOI:https://doi.org/10.1146/annurev.publhealth.25.101802.12300 0 .

[32] Larson, C. et al. 2009. Community Participation in Health Initiatives for Marginalized Populations. Fournal of Ambulatory Care Management. 32, 4 (Oct. 2009), 264-270. DOI:https://doi.org/10.1097/JAC.0b013e3181ba6f74.

[33] Laverack, G. and Wallerstein, N. 2001. Measuring community empowerment: a fresh look at organizational domains.

[34] Lazar, A. et al. 2016. Designing for the Third Hand: Empowering Older Adults with Cognitive Impairments through Creating and Sharing. (2016), 1047-1058.

[35] Lazar, A. et al. 2018. Making as Expression: Informing Design with People with Complex Communication Needs through Art Therapy. CHI '18: Proceedings of the 2018 CHI Conference on Human Factors in Computing Systems (Montreal, 2018).

[36] Lee, H. et al. 2013. Cardiovascular disease among Black Americans: comparisons between the U.S. Virgin Islands and the 50 U.S. states. Public health reports (Washington, D.C. : 1974). 128, 3 (2013), 170-8. DOI:https://doi.org/10.1177/003335491312800307.

[37] Lee, J.M. et al. 2016. A Patient-Designed Do-It-Yourself Mobile Technology System for Diabetes Promise and Challenges for a New Era in Medicine. Jama. 315, 14 (2016), 1447-1448.

[38] Mann, P. 2005. Design for Design: Support for Creative Practice in Computer-Supported Collaborative Work (CSCW) in Design. C\&C '05: Proceedings of the 5th conference on Creativity \& cognition (London, UK, 2005), 240-243.

[39] Marshall, A. and Rode, J. 2018. Deconstructing Sociotechnical Identity in Maker Cultures. GenderIT'18: Proceedings of the 4th Conference on Gender \& IT (Heilbronn, Germany, 2018), 91-100.

[40] Metzler, M.M. et al. 2003. Addressing Urban Health in Detroit New York City, and Seattle Through Community-Based Participatory Research Partnerships.

[41] Muller, M.J. and Druin, A. 2002. Hybridity and Participatory Design-1-DRAFT: Publisher has final version Participatory Design: The Third Space in HCI. The Human Computer Interaction Handbook: Fundamentals, Evolving Technologies and Emerging Applications. 1051-1068.

[42] Orsi, J.M. et al. 2010. Black-White health disparities in the United States and Chicago: a 15-year progress analysis. American journal of public health. 100, 2 (Feb. 2010), 349-56. DOI:https://doi.org/10.2105/AJPH.2009.165407.

[43] Parker, A.G. and Grinter, R.E. 2014. Collectivistic health promotion tools: Accounting for the relationship between culture, food and nutrition. International fournal of Human Computer Studies. 72, 2 (2014), 185-206. DOI:https://doi.org/10.1016/j.ijhcs.2013.08.008.

[44] Racadio, R. et al. 2014. Research at the Margin: Participatory Design and Community Based Participatory Research. In Proceedings of the 13th Participatory Design Conference (2014), 49-52.

[45] Rodil, K. et al. 2012. Enhancing Cross-Cultural Participation through Creative Visual Exploration. PDC '12: Proceedings of the 12th Participatory Design Conference (Roskilde, Denmark, 2012), 81-90.

[46] Rosner, D.K. et al. 2016. Out of Time, Out of Place: Reflections on Design Workshops as a Research Method. Proceedings of the 19th ACM Conference on Computer-Supported Cooperative Work \& Social Computing - CSCW'16 (2016), 1129-1139.

[47] Rothmann, M. et al. 2016. Participatory Design in Health CareParticipation, power and knowledge. PDC'16: Proceedings of the 14th Participatory Design Conference (2016), 127-128.

[48] Sabiescu, A.G. et al. 2014. Emerging spaces in community-based participatory design. Proceedings of the 13th Participatory Design Conference on Research Papers - PDC '14.

[49] Sabiescu, A.G. and Memarovic, N. 2013. Participatory Design for Cultural Representation: A Cultural Transparency Perspective. IFIP Conference on Human-Computer Interaction (Berlin, 2013), 611-618.

[50] Sanders, E. and Westerlund, B. 2011. Experience, exploring and experimenting in and with co-design spaces. Nordic Design Research Conference (Helsinki, 2011), 1-5.

[51] Schlesinger, A. et al. 2017. Intersectional HCI: Engaging Identity through Gender, Race, and Class. Proceedings of the 2017 CHI Conference on Human Factors in Computing Systems CHI' 17.

[52] Schneider, H. et al. 2018. Empowerment in HCI - A Survey and Framework. Proceedings of the 2018 CHI Conference on Human Factors in Computing Systems - CHI '18 (2018), 1-14.

[53] Skogan, W. 2006. Police and Community in Chicago: A Tale of Three Cities - Wesley G. Skogan - Google Books. Oxford.

[54] Smith, M. et al. 2014. Development of a Culturally Relevant Consumer Health Information Website for Harlem, New York. Health Promotion Practice. 15, 5 (2014), 664-674. DOI:https://doi.org/10.1177/1524839914530401.

[55] Steen, M. 2011. Cooperation, Curiosity and Creativity as Virtues in Participatory Design. DESIRE '11: Procedings of the Second 
Conference on Creativity and Innovation in Design (Eindhoven, Netherlands, 2011), 171-174.

[56] Toombs, A. 2015. Enacting Care Through Collaboration in Communities of Makers. CSCW'15 Companion: Proceedings of the 18th ACM Conference Companion on Computer Supported Cooperative Work \& Social Computing (Vancouver, BC, 2015), 81-81.

[57] Toombs, A.L. 2017. Hackerspace Tropes, Identities, and Community Values. DIS '17: Proceedings of the 2017 Conference on Designing Interactive Systems (Edinburgh, 2017), 1079-1091.

[58] Unertl, K.M. et al. 2016. Integrating community-based participatory research and informatics approaches to improve the engagement and health of underserved populations. Fournal of American Medical Informatics Association. 23, (2016), 60-73. DOI:https://doi.org/10.1093/jamia/ocv094.

[59] Vacca, R. 2017. Bicultural: Examining Teenage Latinas' Perspectives on Technologies for Emotional Support. IDC '17: Proceedings of the 2017 Conference on Interaction Design and Children (Stanford, CA, 2017), 117-125.

[60] Vines, J. et al. 2013. Configuring Participation: On How We Involve People In Design. Proceedings of the SIGCHI Conference on Human Factors in Computing Systems (Paris, 2013), 429-438.

[61] Viruell-Fuentes, E.A. et al. 2012. More than culture: Structural racism, intersectionality theory, and immigrant health. Social Science and Medicine. 75, 12 (2012), 2099-2106.
DOI:https://doi.org/10.1016/j.socscimed.2011.12.037.

[62] Wallerstein, N.B. and Duran, B. 2006. Using Community-Based Participatory Research to Address Health Disparities. Health Promotion Practice. 7, 3 (2006), 312-323. DOI:https://doi.org/10.1177/1524839906289376.

[63] Wang, C. and Burris, M.A. 1997. Photovoice: Concept, Methodology, and Use for Participatory Needs Assessment. Health Education and Behavior. 24, 3 (1997), 369-387. DOI:https://doi.org/10.1177/109019819702400309.

[64] Weitzer, R. et al. 2008. Police-Community Relations in Majority-Black City. Journal of Research in Crime and Delinquincy. $\quad 45, \quad 4 \quad$ (2008), $\quad 398-428$. DOI:https://doi.org/10.1177/0022427808322617.

[65] Winschiers-Theophilus, H. et al. 2010. Being Participated-A Community Approach. In Proceedings of the 11th Biennial Participatory Design Conference (Sydney, Australia, 2010), 1-10.

[66] Wong- Villacres, M. et al. 2018. Designing for Intersections. In Proceedings of the 2018 on Designing Interactive Systems Conference 2018 (Hong Kong, 2018), 45-58.

[67] Xie, B. et al. 2012. Co-designing an e-health tutorial for older adults. Proceedings of the 2012 iConference on - iConference '12 (2012), 240-247.

[68] Zimmerman, M.A. 1995. Psychological Empowerment: Issues and Illustrations 1. American fournal of Community Psychology. 23, 5 (1995), 581-599. 